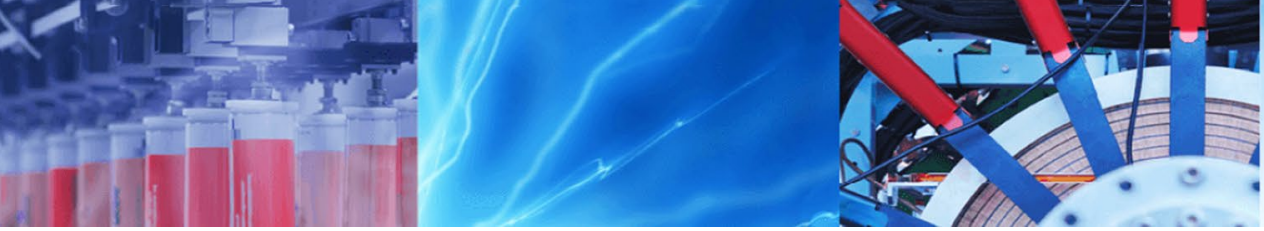

Research Article

\title{
Investigation on rotary ultrasonic assisted end grinding of silicon nitride ceramics
}

\author{
Mohammad Baraheni ${ }^{1} \cdot$ Saeid Amini ${ }^{1}$
}

Received: 3 October 2019 / Accepted: 29 October 2019 / Published online: 6 November 2019

(c) Springer Nature Switzerland AG 2019

\begin{abstract}
In this study, rotary ultrasonic assisted end grinding (RUAEG) of silicon nitride $\left(\mathrm{Si}_{3} \mathrm{~N}_{4}\right)$ was discussed. In addition, comparison of RUAEG with conventional end grinding was carried out. Machining parameters effect on the process was experimentally and statistically distinguished. Moreover, interaction of the influential parameters was discussed and the optimum condition was obtained. It is concluded from interaction plots that ultrasonic vibration influence on surface roughness was greater in lower cutting depths and higher rotational speeds. Moreover, by RUAEG process, it could acquire higher material removal speed with lower thrust force. Exerting ultrasonic vibration on the tool was more influential comparing to other grinding parameters. From morphological examinations, that was concluded RUAEG of ceramics results in lower amount of scratches, diminishing grinding lines and smoothing the surface due to be knocked continuously by the tool.
\end{abstract}

Keywords Silicon nitride · Rotary ultrasonic assisted end grinding · Conventional end grinding · Surface roughness . Statistical study $\cdot$ Morphology

\section{Introduction}

Silicon nitride $\left(\mathrm{Si}_{3} \mathrm{~N}_{4}\right)$ plays an influential role in development of ceramic materials required for advanced applications. Firstly, final cost of this material is low, because $\mathrm{Si}_{3} \mathrm{~N}_{4}$ is easily produced, and silicon and nitrogen are two prevalent elements. Secondly, $\mathrm{Si}_{3} \mathrm{~N}_{4}$, such as silicon carbide ( $\mathrm{SiC})$, is generally considered to be the most non-oxidizing ceramic material that is oxidizing resistant. Thirdly, $\mathrm{Si}_{3} \mathrm{~N}_{4}$ could be readily converted to full density bodies, and the body that is made from this material has high strength [1].

$\mathrm{Si}_{3} \mathrm{~N}_{4}$ has a great strength/weight ratio. This ceramic material has high bond strength, good thermal shock stability (by cause of its small thermal expansion coefficient), good oxidation resistance (compared with other high temperature ceramic materials) and high failure toughness together with high strength in high temperatures. This material $\left(\mathrm{Si}_{3} \mathrm{~N}_{4}\right)$ can withstand mechanical and electrical stresses [2]. In recent decades, ceramics based on $\mathrm{SiC}$ and $\mathrm{Si}_{3} \mathrm{~N}_{4}$ are employed as base materials in gas turbines, car engines, industrial, energy systems, cutting and welding tools, wiring and extrusion processes, wear-resistant parts, bearings and other engineering applications, which are owing to exceptional properties.

Brittle nature of $\mathrm{Si}_{3} \mathrm{~N}_{4}$ makes it impossible to absorb high stresses by using plastic deformation mechanism. Therefore machining and especially grinding processes induce cracks and subsurface damages in the workpiece [3] and under conditions such as periodic mechanical loadings, the workpiece fails [4]. Since engineering ceramics are mostly used as electrical insulators, use of new machining methods is also limited. Because methods such as electrochemical machining or electro discharge machining requires a conductive component [5]. In addition, due to the use of $\mathrm{Si}_{3} \mathrm{~N}_{4}$ in sensitive locations, such as turbine blades, high surface quality is required. To solve

Saeid Amini, amini.s@kashanu.ac.ir | ${ }^{1}$ Faculty of Mechanical Engineering, University of Kashan, Kashan, Iran. 
the machining problem on ceramic parts, some researchers presented laser-machining method [6-9].

Blugan et al. [10] placed a $\mathrm{Si}_{3} \mathrm{~N}_{4}$ part under laser-beam machining. The rays radiated two-dimensionally with a picosecond spacing and cut the $450-\mathrm{mm}$ thickness material. Surface quality of the tests was acceptable. Zhang et al. [11] used traditional grinding and laser grinding method for $\mathrm{Si}_{3} \mathrm{~N}_{4}$ machining and showed that during the laser grinding process, machining forces were significantly reduced in all directions.

On the other hand, in spite of all laser machining advantages, this method has also disadvantages such as high price, difficulty of materials cutting with thickness of greater than $6 \mathrm{~mm}$, low productivity and need for a professional operator [12]. In this regard, other methods have been used such as exerting ultrasonic vibration on the tool $[13,14]$, using tools with various materials such as $\mathrm{SiC}[15]$ and diamond grinding for machining of $\mathrm{Si}_{3} \mathrm{~N}_{4}$.

Since $\mathrm{Si}_{3} \mathrm{~N}_{4}$ and $\mathrm{SiC}$ ceramics have hardness of more than 1500 Vickers, diamond grinding from the sight of economics and surface quality, is the best machining technique to reach the final shape of the ceramic workpieces. This technique is especially useful when cylindrical, curved or other complex surfaces with high surface quality is needed. Various researchers have been studying $\mathrm{Si}_{3} \mathrm{~N}_{4}$ grinding [16, 17]. Stolarski et al. [18] have investigated amount of loading and abrasive grain size in the grinding operation of $\mathrm{Si}_{3} \mathrm{~N}_{4}$ ceramics. Dobrescu et al. [19] studied facial damages in the grinding operation and claimed that facial detriments amount depend on tool grain size.

Ceramic grinding parameters such as cutting velocity, rotational speed, grain size, type of adhesive, etc., should be adjusted correctly to obtain the desired quality.

Principle of using vibration assisted machining methods was initially proposed by Kumabe [20]. Principle of the indicated technique is to add a frequency of up to $40 \mathrm{kHz}$ with a low ultrasonic vibrational amplitude $(2-30 \mu \mathrm{m})$ on the tool-workpiece [21]. Kato and Takeyama [22] stated machining force and chips size will be decreased in ultrasonic assisted drilling comparing to conventional drilling. This phenomenon was also confirmed by Barani et al. [23]. By reducing the force, formation of the built-up edge can also be reduced. Therefore, hole quality will be enhanced with ultrasonic vibration assistance.

Rotary ultrasonic assisted machining process is an operation which is based on exerting ultrasonic vibration on the tool [24]. Firstly rotary ultrasonic assisted surface machining was applied by UhImann et al. [25] and influence of different tools in various cutting depths and rotational speeds on surface quality and material removal speed were examined. Moreover, Amini et al. [26] investigated thrust force, burr and chip in vibration assisted drilling and conventional drilling. Besides, rotary ultrasonic assisted drilling of reinforced composites with glass fibers [27, 28] and carbon fibers [29] was investigated in our last researches that lower delamination was obtained comparing to conventional drilling. Li et al. [30] studied rotary ultrasonic assisted machining of ceramic matrix composites and it was also shown in this study that feeding speed has an influential effect on the machining force. Some researchers also conducted multi-objective optimization on rotary ultrasonic assisted machining of different materials [31-33].

Previous studies show that $\mathrm{Si}_{3} \mathrm{~N}_{4}$ ceramics due to special applications in various industries in special conditions such as high temperature, high wear, etc. situations, as well as the need to be formed in different or to achieve high surface quality, attracted attention of numerous researchers. Rotary ultrasonic assisted end grinding method that has been previously introduced, like conventional grinding techniques, could cause surface and subsurface damages. Therefore, it is required further researches.

Based on previous researches in the rotary ultrasonic assisted end grinding (RUAEG) process, parameters of feeding speed, cutting depth and rotational speed are the superb elements affecting grinding force and surface quality [34]. In this study, in spite of most previous researches that used water as a coolant, establishing $\mathrm{CO}_{2}$ gas will be examined. Afterwards, influence of machining parameters in conventional end grinding (CEG) and RUAEG processes on thrust force and surface quality experimentally, morphologically and statistically will be deeply investigated.

\section{Materials and methods}

In this study, experimental tests were carried out in two ways: CEG and RUAEG. Experiments were conducted on a china made CNC milling machine. A special fixture designed for the $\mathrm{Si}_{3} \mathrm{~N}_{4}$ workpieces. Ultrasonic vibration generator (made in KIA Co., Taiwan) was also used in order to perform RUAEG process. System resonance frequency and vibration amplitude were $20.5 \mathrm{kHz}$ and $15 \mu \mathrm{m}$, respectively. Ultrasonic vibration amplitude was measured by PU-09 gap sensor (AEC Co.). Cooling gas $\left(\mathrm{CO}_{2}\right)$ pressure was 5 bar. Particular tool was used for RUAEG operation. Tool components were transducer, horn and diamond core tool. Experiments establishment has been demonstrated in Fig. 1.

Thrust forces were obtained via Kistler type 9257B dynamometer and then analyzed by Dynoware application. Surface roughness was measured by Hommel Etamic roughness meter device. To measure surface roughness, probe moves $4 \mathrm{~mm}$ in length axis onto a work piece and measures distance of 10-point peaks and valleys over a source line, then reports mean of the numbers as surface 
Fig. 1 Experiments components
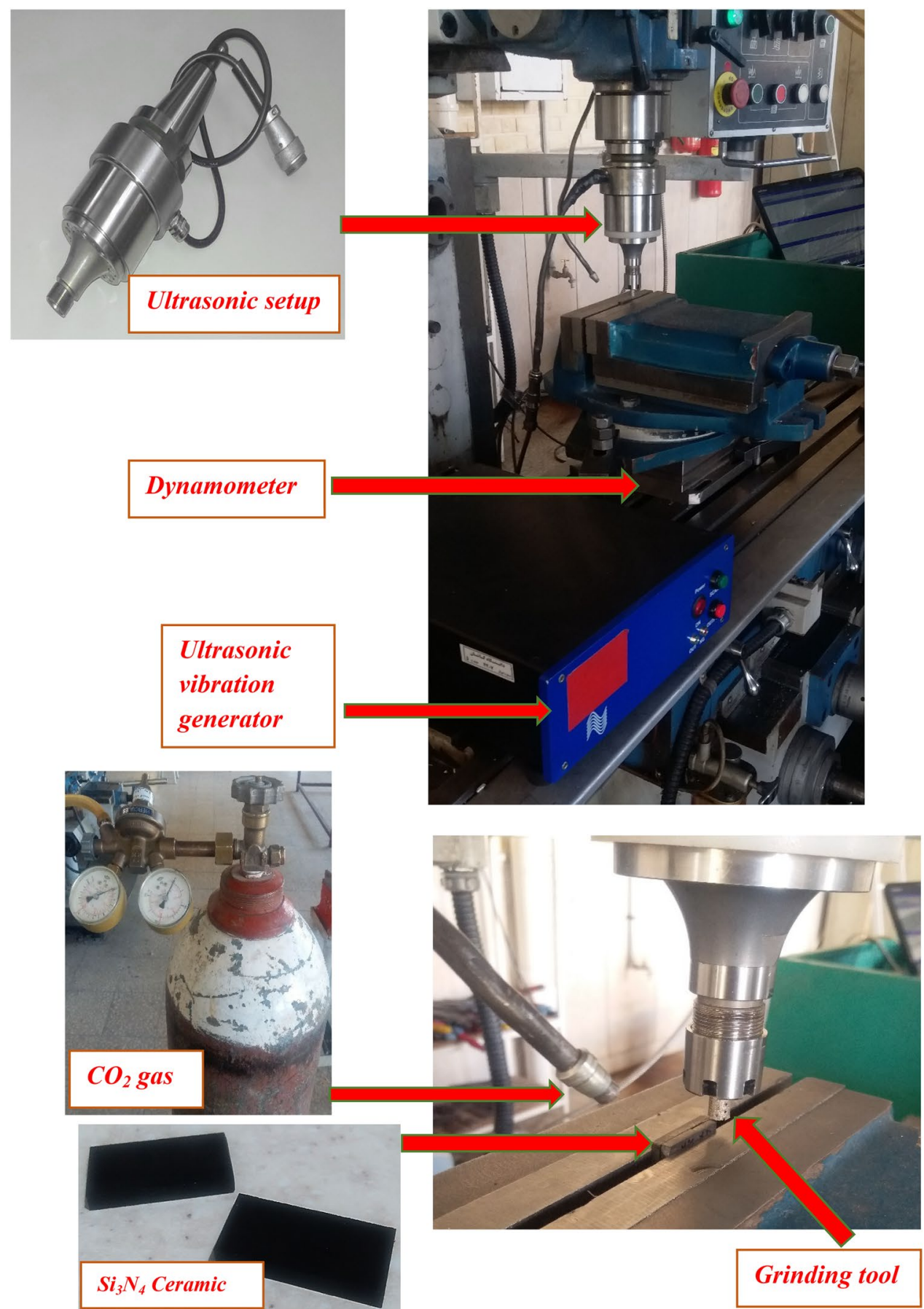

roughness. Surface roughness measurement was carried out in three places and the average value reported. Besides, Easson Visual Measurement Machine (VMM) was used in order to determine delamination on the holes.

$\mathrm{Si}_{3} \mathrm{~N}_{4}$ workpieces are in rectangular shape (3* $12 * 50 \mathrm{~mm}$ ) from Lianyungang Highborn Technology Co., Ltd. Density, Elastic modulus and Poisson's ratio of used $\mathrm{Si}_{3} \mathrm{~N}_{4}$ are $3.26 \mathrm{~g} / \mathrm{cm}^{3}, 310 \mathrm{GPa}$ and 0.25 .

Design of experiments in CEG and RUAEG is presented in Table 1.

\section{Results and discussion}

\subsection{Thrust force}

Thrust force data is transformed from Dynoware software to Microsoft Excell software and analyzed. To conduct experiments, in the beginning, ultrasonic vibration generator is turned on in order to perform RUAEG process. Then, when the tool reaches the middle of the workpiece, the generator is turned off to conduct CEG process. In each 
Table 1 Design of experiments

\begin{tabular}{llll}
\hline & $\begin{array}{l}\text { Feeding } \\
\text { speed } \\
(\mathrm{mm} / \\
\mathrm{min})\end{array}$ & $\begin{array}{l}\text { Rotational } \\
\text { speed }(\mathrm{rpm})\end{array}$ & Cutting depth $(\mu \mathrm{m})$ \\
\hline 1st test group & $\begin{array}{c}3,6,8,12, \\
16,24\end{array}$ & 5440 & 60 \\
2nd test group & 8 & $\begin{array}{c}1110,1750, \\
2220,2720,\end{array}$ \\
& \multicolumn{5}{c}{3500,5440} \\
3rd test group & 8 & 5440 & $30,40,60,80,100,120$ \\
\hline
\end{tabular}

process, there are three areas in thrust force measurement: beginning, stable and ending. Measured thrust force is belonged to stable part. Measuring area of thrust force in both processes is plotted in Fig. 2.

Figure 3 exhibits machining parameters influence on thrust force. As depicted in Fig. 3a, increasing feeding speed increases thrust force in both processes. Based on the mechanics of cutting metals, by feeding speed inclining, tool and workpiece engagement surface increases, and as a result, the thrust force increases.

As depicted in Fig. 3a, thrust force in CEG increases more as compared to RUAEG. In RUAEG, thrust force increases with a smoother slope that is because of change in the nature of the material removal process.

Another investigation in the rotary ultrasonic machining (RUM) operation shows that low feeding speed reduces the thrust force, which is due to the high micro-cracks [35].

As shown in Fig. 3b, in both CEG and RUAEG, thrust force on the tool is reduced by increasing the rotational speed. By increasing cutting velocity, cutting plate area or initial deformation region volume decreases, so less energy is required to remove the material and increases cutting efficiency. Also, with increasing cutting velocity, frictional force between tool and the workpiece decreases $[36,37]$.

Moreover, according to Fig. 3b, rotational speed increment induces more thrust force reduction in RUAEG compared to CEG. Generally, vibration cutting mechanism that causes interruption of the tool-workpiece contact, results in average thrust force reduction compared to machining without vibration [38].

On the other hand, thrust force reduction initially occurs suddenly and then decreases softly [39].

Similar changes have been observed in the thrust force of the rotary ultrasonic assisted milling of BK7 and K9 glass by rotational speed variation $[35,40]$.

Based on Fig. $3 \mathrm{c}$ as cutting depth increases, deformation of the material will be changed from ductile to brittle. Hence, more force will be exerted on the tool. Moreover, in RUAEG, discontinuous tool-workpiece contact results in lower average thrust force in contrast with CEG. Furthermore, as demonstrated in Fig. $3 c$ in larger cutting depths, more thrust force is observed. In larger cutting depths, more chips are created and remained under the tool or adhered to that, which induce more thrust force in CEG. In RUAEG, because of alternative motion of the tool, chips could be escaped more easily by $\mathrm{CO}_{2}$ gas and therefore more thrust force reduction are observed in larger cutting depths.

As demonstrated in Fig. 3, thrust force is effectively reduced while using ultrasonic vibrations. During RUAEG process, due to ultrasonic vibration, abrasive grain moves in a sinusoidal curve. Since the tool and workpiece interrupts intermittently, the workpiece is continuously impacted in this process, while in CEG, this state does not exist. In RUAEG process, the workpiece suffers a severe impact. Friction decreases due to the reduced
Fig. 2 Thrust force measurement in $5440 \mathrm{rpm}$ rotational speed; $16 \mathrm{~mm} / \mathrm{min}$ feeding speed; $60 \mu \mathrm{m}$ cutting depth

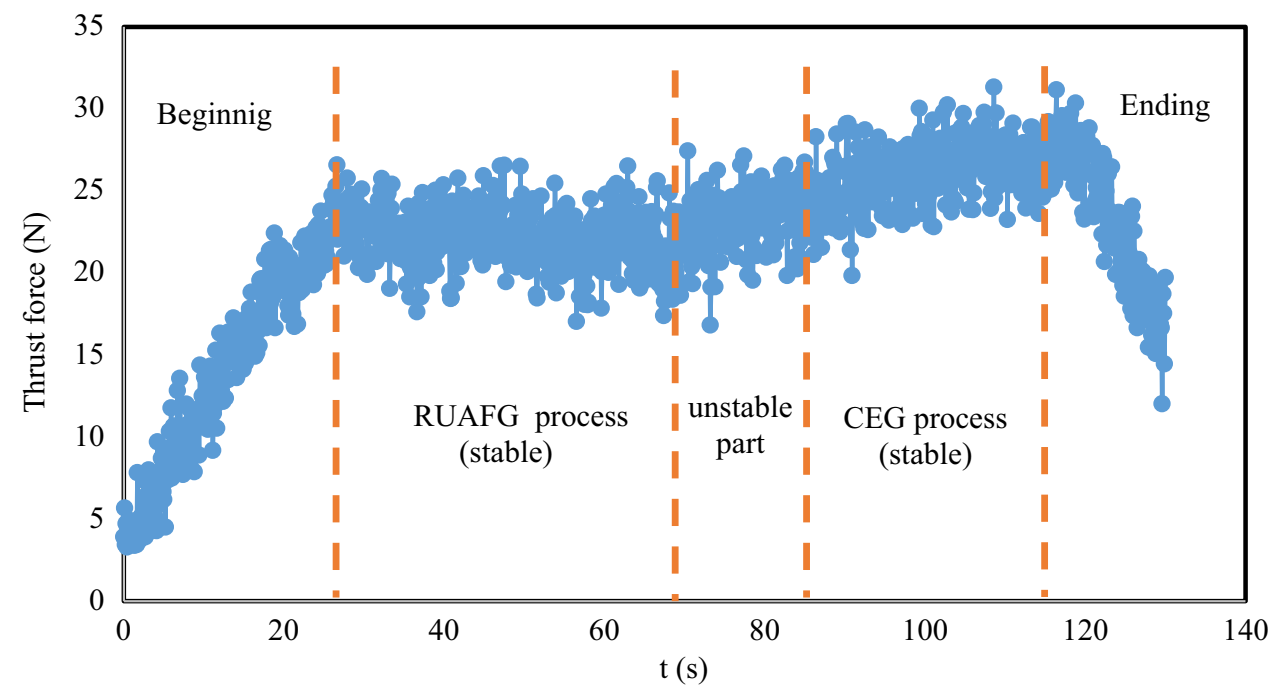



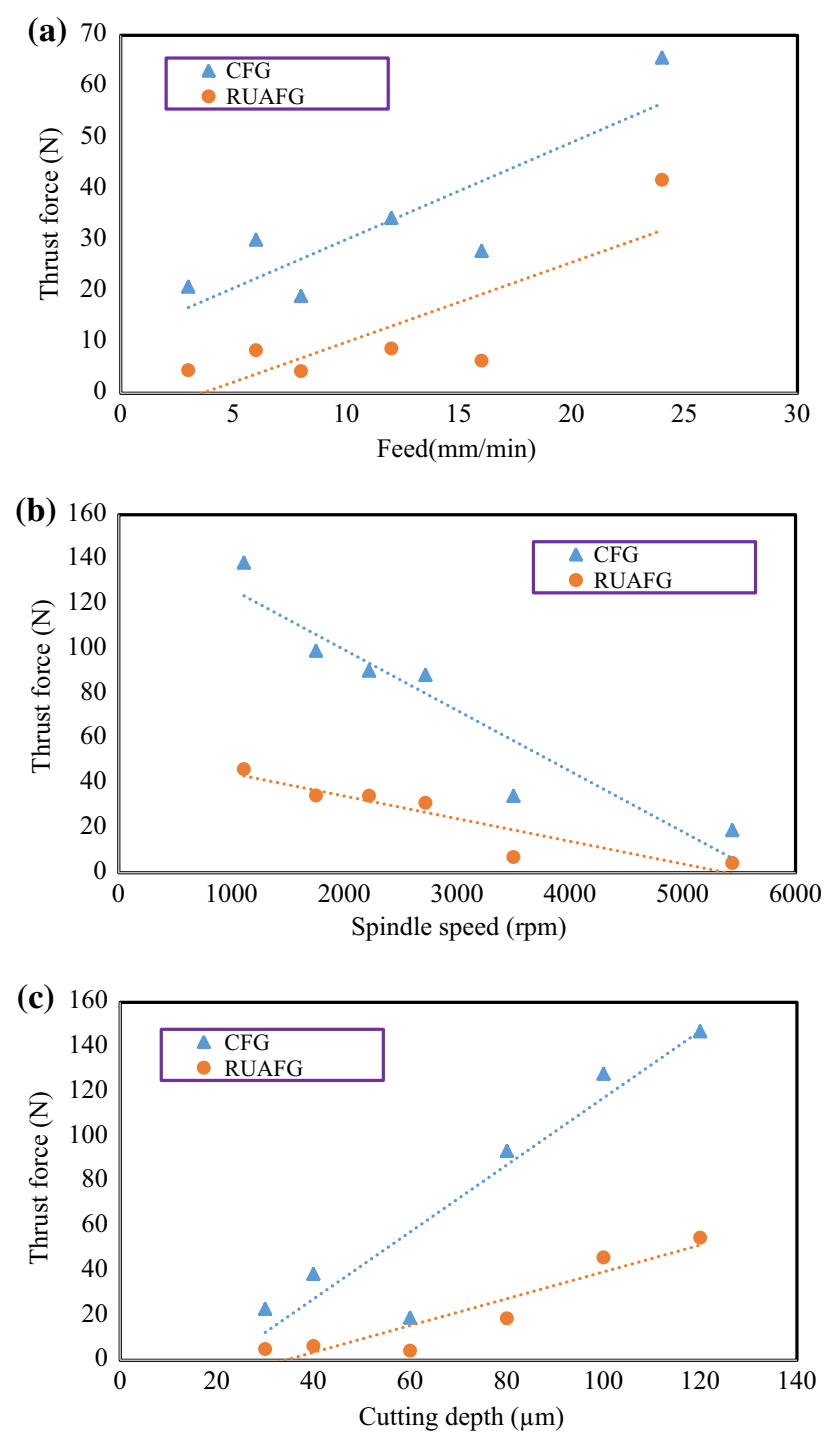

Fig. 3 Effects of machining parameters on thrust force

adhesion of the chip to the tool, which it was because of reduction in length of chip-tool contact. On the other hand, in RUAEG, by exerting vibration, relative speed of tool head will not be zero. While in CEG, relative speed of the tool is zero which causes severe material plastic deformity forward the tool. In CEG, because of uninterrupted tool-workpiece contact, tool wears more rapidly comparing to RUAEG that afterwards induces more thrust force.

Other factors affecting thrust force reduction in RUAEG consist of breaking and crushing of chips in RUAEG method that is due to longitudinal collisions of tool and workpiece which consequently, more space between tool and workpiece will be created and chips could escape easier [41].
In this research, by using Minitab software, analysis of variance (ANOVA) was conducted on thrust force outcomes (Table 2).

By using results of Table 2 and Minitab software, statistical linear regression analysis between thrust force results and rotational speed, cutting depth and feeding speed was performed and a relationship was presented in both CEG and RUAEG (Table 3).

The $P$ value in Table 2 indicates that the difference between the mean of the data is significant. The smaller the $P$ value for one parameter, more important that parameter will be.

Sum of squares and mean of squares are used to calculate the $P$ value. Almost, researchers report $P$ value in their papers and used in calculations. Mean of squares is obtained through dividing the sum of squares by the degree of freedom and indicates change of each parameter influence upon the outcome parameter (thrust force). Based on Table 2, ultrasonic vibration has the greatest effect $(29.36 \%)$ on thrust force reduction. Cutting depth, rotational speed and feeding speed are in the next orders. In this research, due to the degree of freedom uniformity, mean of squares and sum of squares were equal. On the other hand, sum of squared error in this study shows that $4.29 \%$ of data variation cannot be predicted using this model, which is negligible.

Also, high value of R-Squared $(92.09 \%)$ indicates that the ratio of thrust force variation to input factors towards specifying a linear regression correlation is at a high reliability level.

To illustrated the relationship between different parameters and their impact on machining results, interaction plot is depicted in Fig. 4. Since all the lines in the Fig. 4 are parallel and without interrupt, results that they have no interaction. In Fig. 4a, it is observed that in higher feeding speeds, effect of the ultrasonic vibration parameter is greater and results in more reduction in the thrust force. However, in the lower feeding speeds, this effect is diminished. Of course, feeding speed variation in lower feeding speeds also have slight effect on the thrust force variation. Otherwise, in the case of RUAEG, we will have lower amount of thrust force increase by feeding speed increment and the workpiece could be machined by higher feeding speeds and also lower thrust force. That is obvious in Fig. 4e, h which in the case of RUAEG, the effect of increasing the cutting depth decreases, and in this case, greater cutting depths could be utilized comparing to CEG. Therefore, higher material removal speed is acquired without the thrust force increasing. Reducing the thrust force reduces tool wearing, which in turn results in longer tool life in case of RUAEG. In Fig. 4k, it is also observed that the distance between the points in the RUAEG mode is closer and, as a result, thrust force increases slower by rotational 
Table 2 ANOVA results of thrust force

\begin{tabular}{lrrrlrl}
\hline Parameters & $d f$ & Sum of squares & Mean of squares & Contribution (\%) & F-value & $P$ value \\
\hline $\mathrm{C}$ & 1 & 1450.8 & 1450.8 & 23.11 & 10.61 & 0.004 \\
$\mathrm{~F}$ & 1 & 89.9 & 89.9 & 3.20 & 0.66 & 0.427 \\
$\mathrm{R}$ & 1 & 2.7 & 2.7 & 19.02 & 0.02 & 0.890 \\
$\mathrm{U}$ & 1 & 785.9 & 785.9 & 29.36 & 5.75 & 0.027 \\
$\mathrm{C}^{*} \mathrm{C}$ & 1 & 1623.0 & 1623.0 & 3.87 & 11.87 & 0.003 \\
$\mathrm{~F}^{*} \mathrm{~F}$ & 1 & 176.6 & 176.6 & 2.10 & 1.29 & 0.270 \\
$\mathrm{R}^{*} \mathrm{R}$ & 1 & 76.2 & 76.2 & 1.49 & 0.56 & 0.464 \\
$\mathrm{C}^{*} \mathrm{U}$ & 1 & 53.9 & 53.9 & 4.51 & 0.39 & 0.538 \\
$\mathrm{~F}^{*} \mathrm{U}$ & 1 & 34.3 & 34.3 & 0.56 & 0.25 & 0.622 \\
$\mathrm{R}^{*} \mathrm{U}$ & 1 & 493.9 & 493.9 & 3.52 & 3.61 & 0.073 \\
$\mathrm{C}^{*} \mathrm{C}{ }^{*} \mathrm{C}$ & 1 & 1205.3 & 1205.3 & 2.76 & 8.82 & 0.008 \\
$\mathrm{~F}^{*} \mathrm{~F}^{*} \mathrm{~F}$ & 1 & 421.3 & 421.3 & 0.67 & 3.08 & 0.095 \\
$\mathrm{R}^{*} \mathrm{R}^{*} \mathrm{R}$ & 1 & 156.6 & 156.6 & 0.26 & 1.15 & 0.298 \\
$\mathrm{C}^{*} \mathrm{C}{ }^{*} \mathrm{U}$ & 1 & 350.9 & 350.9 & 0.57 & 2.57 & 0.126 \\
$\mathrm{~F}^{*} \mathrm{~F}^{*} \mathrm{U}$ & 1 & 150.6 & 150.6 & 0.29 & 1.10 & 0.307 \\
$\mathrm{R}^{*} \mathrm{R}^{*} \mathrm{U}$ & 19 & 260.2 & 260.2 & 0.43 & 1.90 & 0.184 \\
Error & 15 & 2597.2 & 136.7 & 4.29 & & \\
Lack of fit & 4 & 2597.2 & 173.1 & 4.29 & & \\
Pure error & 35 & 0.0 & 0.0 & 0.0 & 100 & \\
Total & & & & & & \\
\hline & & & & & &
\end{tabular}

Table 3 Statistical relationship between thrust force and input parameters

\begin{tabular}{ll}
\hline Process & Regression model \\
\hline CEG & Thrust force $=283.0-7.96 C+5.27 F-0$. \\
& $0079 R+0.1223 C^{*} C-0.615 F^{*} F-0.0$ \\
& $00015 R^{*} R-0.000476 C^{*} C^{*} C+0.023$ \\
& $6 F^{*} F^{*} F$ \\
RUAEG & Thrust force $=141.7-7.27 C+7.35 F+0$. \\
& $0363 R+0.1111 C^{*} C-0.769 F^{*} F-0.0$ \\
& $00019 R^{*} R-0.000476 C^{*} C^{*} C+0.023$ \\
& $6 F^{*} F^{*} F$ \\
& \\
R-squared $=92.09 \%$ & \\
\hline
\end{tabular}

$F$ feed speed, $R$ rotational speed, $C$ cutting depth

speed decrement. In general, it can be concluded from the diagrams that by applying vibrations, higher feeding speed and cutting depth and lower rotational speed could be exerted that is a significant outcome. Therefore, higher material removal speed can be acquired.

\subsection{Surface roughness}

By Hommel Etamic roughness meter device, surface roughness plots derived. One sample plot is demonstrated in Fig. 5.

Surface roughness is influenced by the input machining factors. Different investigations have been performed to examine various machining parameters effect on surface roughness. Cong et al. [42] inspected the effect of every process input or their composition in ultrasonic assisted machining of stainless steel. Ultrasonic vibration and its interaction with rotational speed were the most influential parameter on the surface roughness.

In this study, to evaluate the surface quality, mean of ten points surface roughness is used. Figure 6 depicts diverse machining condition effects on surface roughness.

In Fig. 6a, surface roughness is depicted in different feeding speeds. The higher the feeding speed, the greater the surface roughness. The lowest surface roughness occurs at the minimum feeding speed. In general, due to the use of carbon dioxide gas for cooling and gas penetration in the tool-workpiece contact area, friction coefficient decreases [43] and hence surface roughness is reduced.

Also, in higher feeding speed conditions, machining area temperature increases, the friction coefficient increases, and hence surface roughness increases.

In addition, as illustrated in Fig. $6 \mathrm{~b}$, rotational speed increment results in surface roughness reduction. Zhang et al. [44] examined various process variables influence on RUM of K9 crown crystal. Compressed air is exerted on the machining area to cool the tool-workpiece space. The results indicated an increase in surface roughness by feeding speed increment, while by increasing the rotational speed, surface roughness reduces. This surface roughness decline in rotary ultrasonic machining process was associated with the material removal named as "microchips" in ultrasonic assisted machining, while in the traditional 


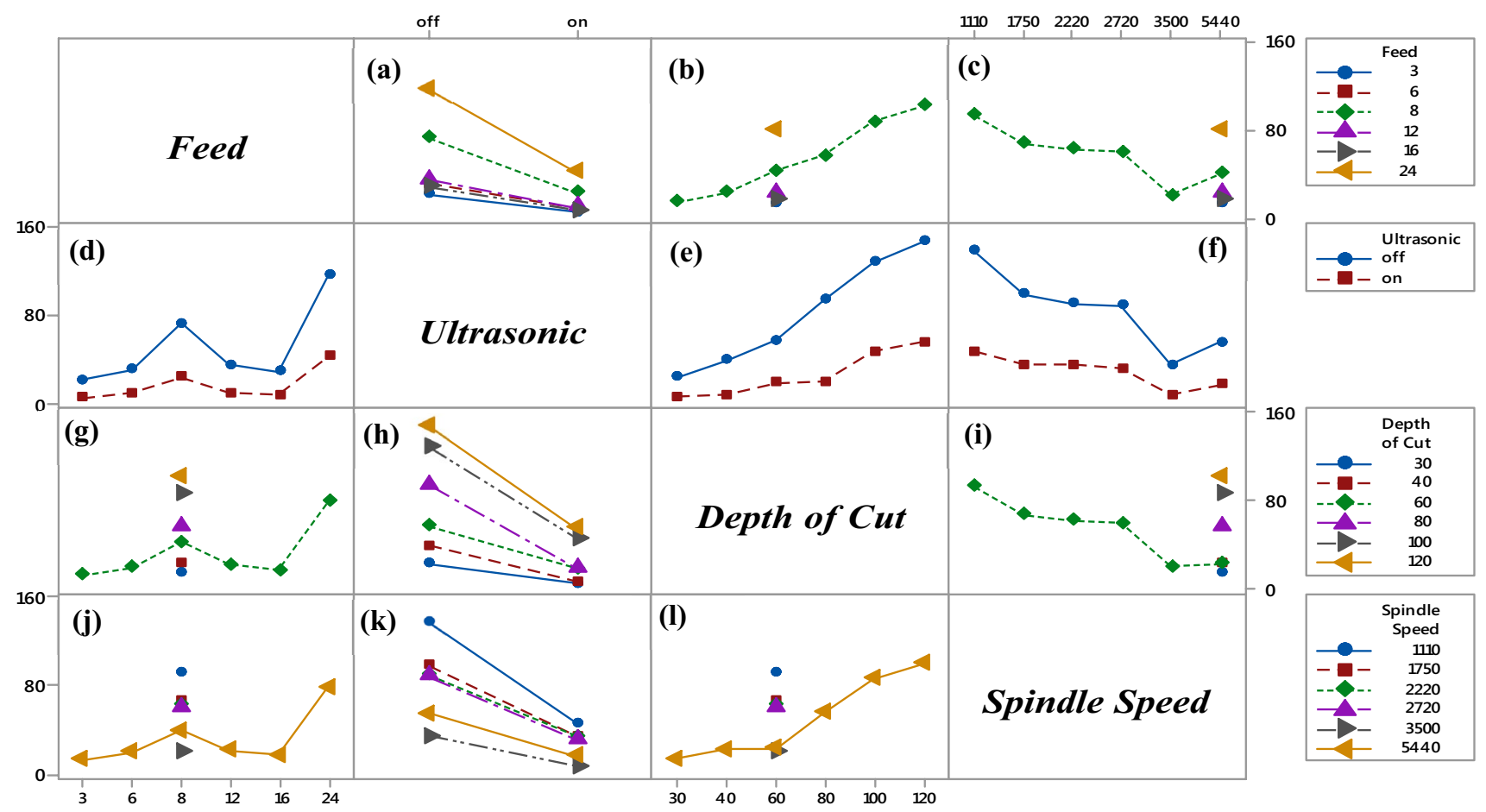

Fig. 4 Interaction plot of thrust force

Fig. 5 Surface roughness plot in RUAEG process and in rotational speed of $5440 \mathrm{rpm}$; feeding speed of $12 \mathrm{~mm} / \mathrm{min}$; cutting depth of $60 \mu \mathrm{m}$

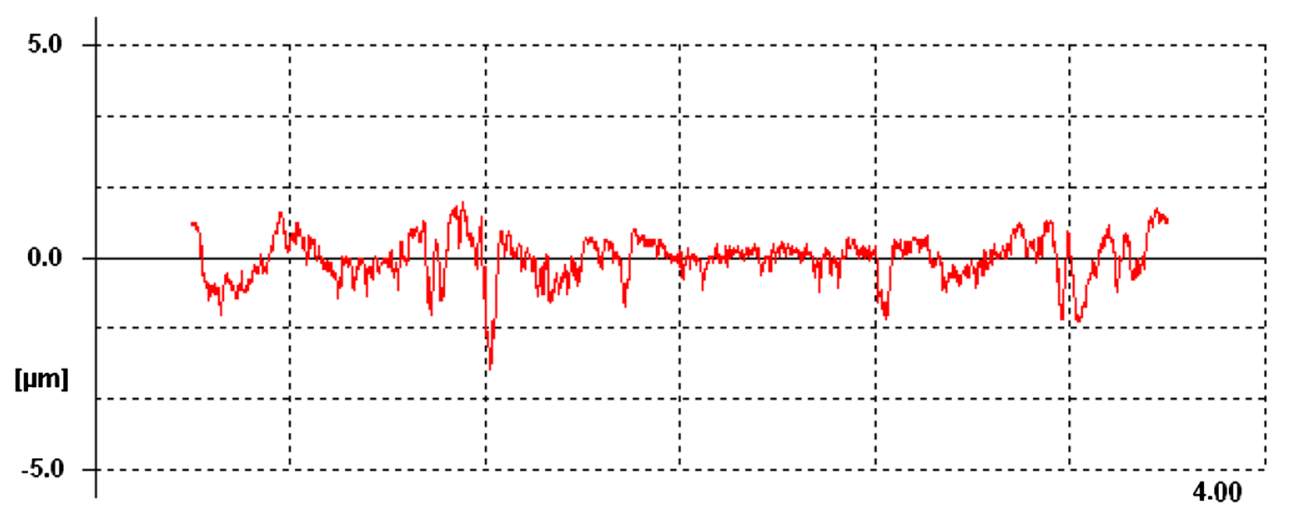

process, larger chips produce a cavity and the surface roughness increases accordingly. In RUM process, lower thrust force provide more finished surface. Kuruc et al. [45] experimentally examined surface roughness in RUM of PCBN (Polycrystalline Cubic Boron-Nitride) and observed this process is able to provide better surface quality for hard materials. Higher rotational speed and larger abrasive grains lessen surface roughness.

Furthermore, low rotational speed results in changing deformation mechanism from ductile to brittle deformation. Brittle deformation induces cracks and scratches on the surface and hence, surface quality will be worse.

On the other hand, it can be said that the greater the cutting depth in the workpiece, amount of wear and therefore deformation of the tool increases and the generated heat increases. Besides, with constant rotational speed and increasing cutting depth, the attrition wear (adhesion wear) increases and tendency to self-sharpenability via grain-separating decreases that results in creation of larger flattened areas and larger thrust force. Thus amount of surface roughness will increase [46] that results of experiments in this study in Fig. $6 \mathrm{c}$ demonstrates the same condition. Also, increase in the wear speed of the grinding tool as a result of cutting depth increment, causes abrasive grains to go out of their places [47]. Additionally, increasing cutting depth results in increasing contact area of the abrasive grain-workpiece that causes tangential force increment. As a result, friction coefficient increases too.

Chipping occurs when the abrasive grit sufficiently penetrates in the workpiece. This amount of cutting by 

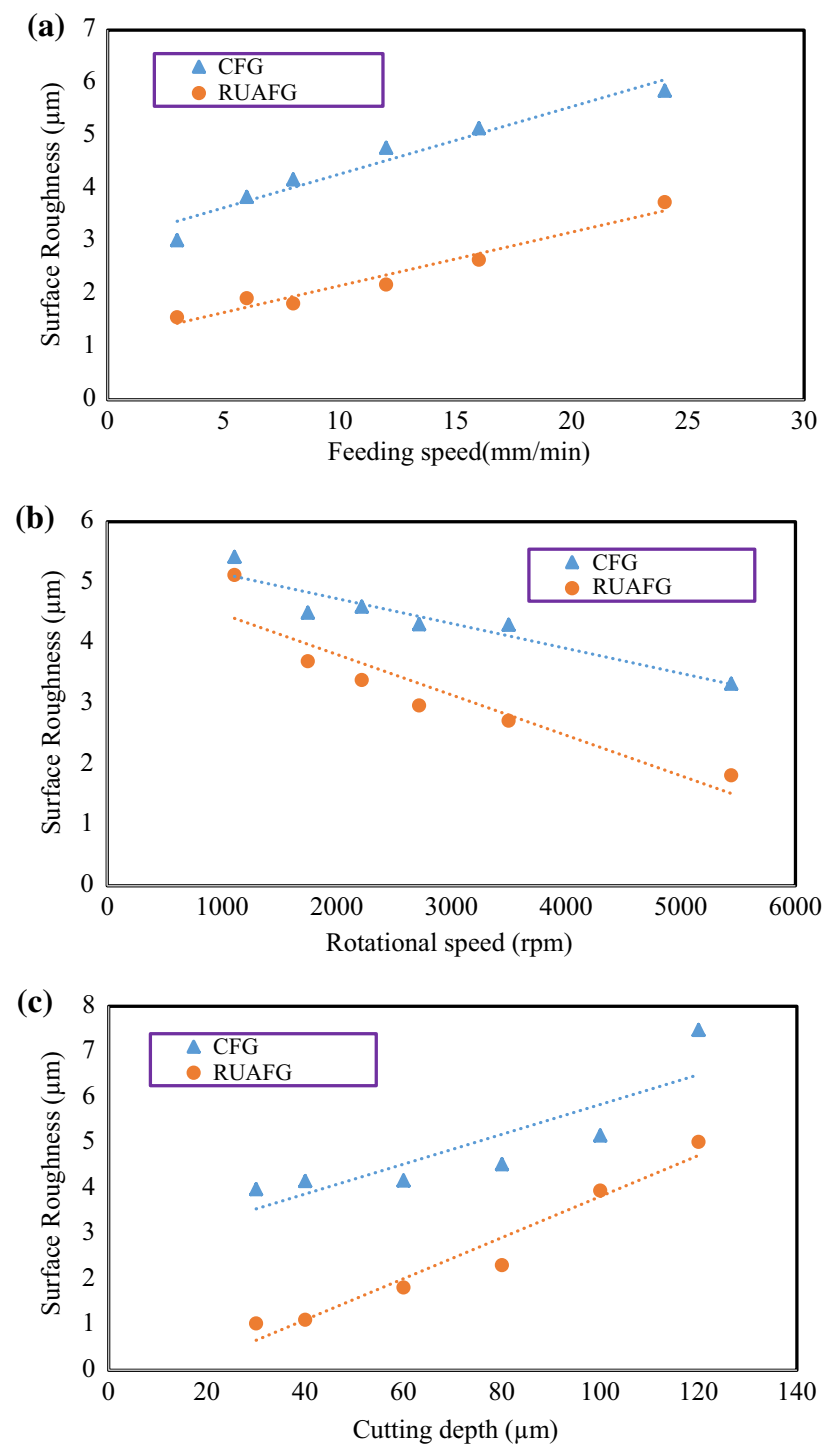

Fig. 6 Machining parameters effect on surface roughness

an abrasive grain corresponds to the undeformed chip thickness. On the other hand, the amount of surface roughness is directly correlated with the undeformed chip thickness [48]. Factors such as friction coefficient, elastic deformation and plastic deformation in grinding area lead to change in the amount of undeformed chip thickness. The less the amount of undeformed chip thickness, the better surface quality will be obtained [48]. Cutting depth increasing and carbon dioxide gas blowing reduce the friction coefficient and, as a result, decrease the undeformed chip thickness [49] and induce less surface roughness.
In the following, statistical analysis of variance between surface roughness data and input parameters is conducted that outcomes are detailed in Table 4.

In the following, using the information in Table 4, analysis of linear regression for surface roughness is generated (Table 5).

From the interaction plot in Fig. 7, as discussed in last section, that could obtain information about interaction of the machining parameters. That is seen from Fig. 7a that up to $16 \mathrm{~mm} / \mathrm{min}$ in RUAEG process, the points are closer comparing to the traditional machining process, which can result in higher surface quality at the same higher feeding speeds. That is obtained from Fig. 7e, ultrasonic vibration is more influential on surface roughness in lower cutting depths. Moreover, in RUAEG, surface roughness can be further affected and reduced by reduction of cutting depth. According to Fig. $7 f$, $k$, ultrasonic vibration effects are more evident at higher rotational speeds. In addition, surface roughness at rotational speeds from 1110 to $5440 \mathrm{rpm}$, decreases faster in RUAEG compared to CEG. These results are in accordance with the previous explanations.

\subsection{Observation of surface quality}

Quality of the machined surfaces in CEG and RUAEG processes is shown in Fig. 8. From Fig. 8a, it is concluded that by ultrasonic addition, machining lines that were created by abrasive grains contact with ceramic surfaces, could be deduced and surface quality will be improved. Due to applying ultrasonic waves, the tool impacts on the surface and causes the surface to be knocked, resulting in a smoother surface (Fig. 8b).

In addition, according to Fig. 9, it can be concluded that by feeding speed decrement, surface cracks caused by the collision of tools with $\mathrm{Si}_{3} \mathrm{~N}_{4}$ are reduced and the surface becomes even more homogenous. Feeding speed increment induces higher applying force on the workpiece that leads to crack creation. Feeding speed variation has been demonstrated in two CEG and RUAEG processes. That is observed in RUAEG process, effect of feeding speed deduction is lower and even better surface quality is obtained at higher feeding speeds. Machining lines in CEG process (Fig. 9d) is diminished in ultrasonic assisted process (Fig. 9b), and more uniform surface is achieved.

It is evident from Fig. 10 that by reducing the rotational speed due to thrust force increase, the material will be dug from workpiece surface and lower surface quality will be acquired. At higher rotational speeds (Fig. 10c), amount of scratches are lowered and distributed in the form of small cavities on the surface. In RUAEG mode (Fig. 10a, b), these 
Table 4 Surface roughness ANOVA results

\begin{tabular}{|c|c|c|c|c|c|c|}
\hline Parameters & $d f$ & Sum of squares & Mean of squares & Contribution(\%) & F-Value & P-Value \\
\hline C & 1 & 0.0012 & 0.0012 & 23.77 & 0.02 & 0.889 \\
\hline $\mathrm{F}$ & 1 & 0.1370 & 0.1370 & 7.52 & 2.34 & 0.143 \\
\hline $\mathrm{R}$ & 1 & 0.5490 & 0.5490 & 12.71 & 9.36 & 0.006 \\
\hline U & 1 & 0.0421 & 0.0421 & 42.96 & 0.72 & 0.407 \\
\hline$C * C$ & 1 & 0.0090 & 0.0090 & 4.17 & 0.15 & 0.700 \\
\hline$F^{*} \mathrm{~F}$ & 1 & 0.0008 & 0.0008 & 0.00 & 0.01 & 0.911 \\
\hline $\mathrm{R} * \mathrm{R}$ & 1 & 0.4011 & 0.4011 & 1.16 & 6.84 & 0.017 \\
\hline$C^{*} U$ & 1 & 0.5960 & 0.5960 & 0.17 & 10.16 & 0.005 \\
\hline$F^{*} U$ & 1 & 0.3567 & 0.3567 & 0.33 & 6.08 & 0.023 \\
\hline$R^{*} U$ & 1 & 0.2043 & 0.2043 & 3.83 & 3.48 & 0.078 \\
\hline$C * C^{*} C$ & 1 & 0.1111 & 0.1111 & 0.18 & 1.89 & 0.185 \\
\hline$F * F^{*} F$ & 1 & 0.0025 & 0.0025 & 0.00 & 0.04 & 0.838 \\
\hline$R * R^{*} R$ & 1 & 0.3387 & 0.3387 & 0.46 & 5.77 & 0.027 \\
\hline$C^{*} C^{*} U$ & 1 & 0.4555 & 0.4555 & 0.74 & 7.77 & 0.012 \\
\hline$F^{*} F^{*} U$ & 1 & 0.2860 & 0.2860 & 0.41 & 4.88 & 0.040 \\
\hline$R^{*} R^{*} U$ & 19 & 0.0743 & 0.0743 & 0.10 & 1.27 & 0.274 \\
\hline Error & 15 & 1.1145 & 0.0587 & 0.50 & & \\
\hline Lack of fit & 4 & 0.6441 & 0.0429 & 0.87 & 0.37 & 0.932 \\
\hline Pure error & 35 & 0.4704 & 0.1176 & 0.63 & & \\
\hline Total & & & & 100 & & \\
\hline
\end{tabular}

Table 5 Statistical relationship between surface roughness and input parameters

\begin{tabular}{ll}
\hline Process & Regression model \\
\hline CEG & $\begin{array}{c}\text { Surface rough- } \\
\text { ness }=7.16-0.0072 C+0.206 F-0.00360 R-0.000288 C{ }^{*} C-0.0013 F * F+0.000001 R * R+0.000005 C * C * C-0.000058 F * F * F\end{array}$ \\
RUAEG $\quad \begin{array}{r}\text { Surface rough- } \\
\text { ness }=6.13+0.0647 C-0.007 F-0.00450 R-0.000692 C * C+0.0054 F * F+0.000001 R * R+0.000005 C * C * C-0.000058 F^{*} F * F\end{array}$ \\
$R-$ squared $=97.24 \%$
\end{tabular}

holes are lessened and even at lower rotational speeds (Fig. 10a) the amount of cavities is less than the same condition in CEG (Fig. 10d).

Figure $11 \mathrm{a}, \mathrm{b}$ depicts that surface quality gets much worse owing to cutting depth incline and indicates high impact of cutting depth parameter on surface quality which was also obtained from analysis of variance in the previous section. Increasing cutting depth induces surface roughness increase. By increasing cutting depth, distance of top of the abrasive grain from machining surface is increased and thereupon more material will be machined by the grinding tool that leads to material digging (Fig. 11) and gives the low surface quality. In addition, as previously observed, applying ultrasonic vibration reduces amount of cavities and the better surface quality will be acquired comparing to CEG.

\subsection{Optimization}

Using optimization tool in Minitab software and regression models (Tables 3, 5); optimal values for RUAEG and CEG on $\mathrm{Si}_{3} \mathrm{~N}_{4}$ ceramics are depicted in Fig. 12. Since thrust force and surface roughness have been reduced by applying vibration in all experiments, the CEG mode is not considered to find out optimum condition. Optimum conditions actually represent the best surface quality with the least created force that according to Fig. 12, with $3 \mathrm{~mm} / \mathrm{min}$ feeding speed, $5440 \mathrm{rpm}$ rotational speed and $30 \mu \mathrm{m}$ cutting depth in RUAEG mode could be obtained. In Fig. 12, value of "d" represents the individual desirability for each thrust force and surface roughness. The value of " $D$ " also indicates the combination desirability of response parameters (Eq. 1). As both of "D" 


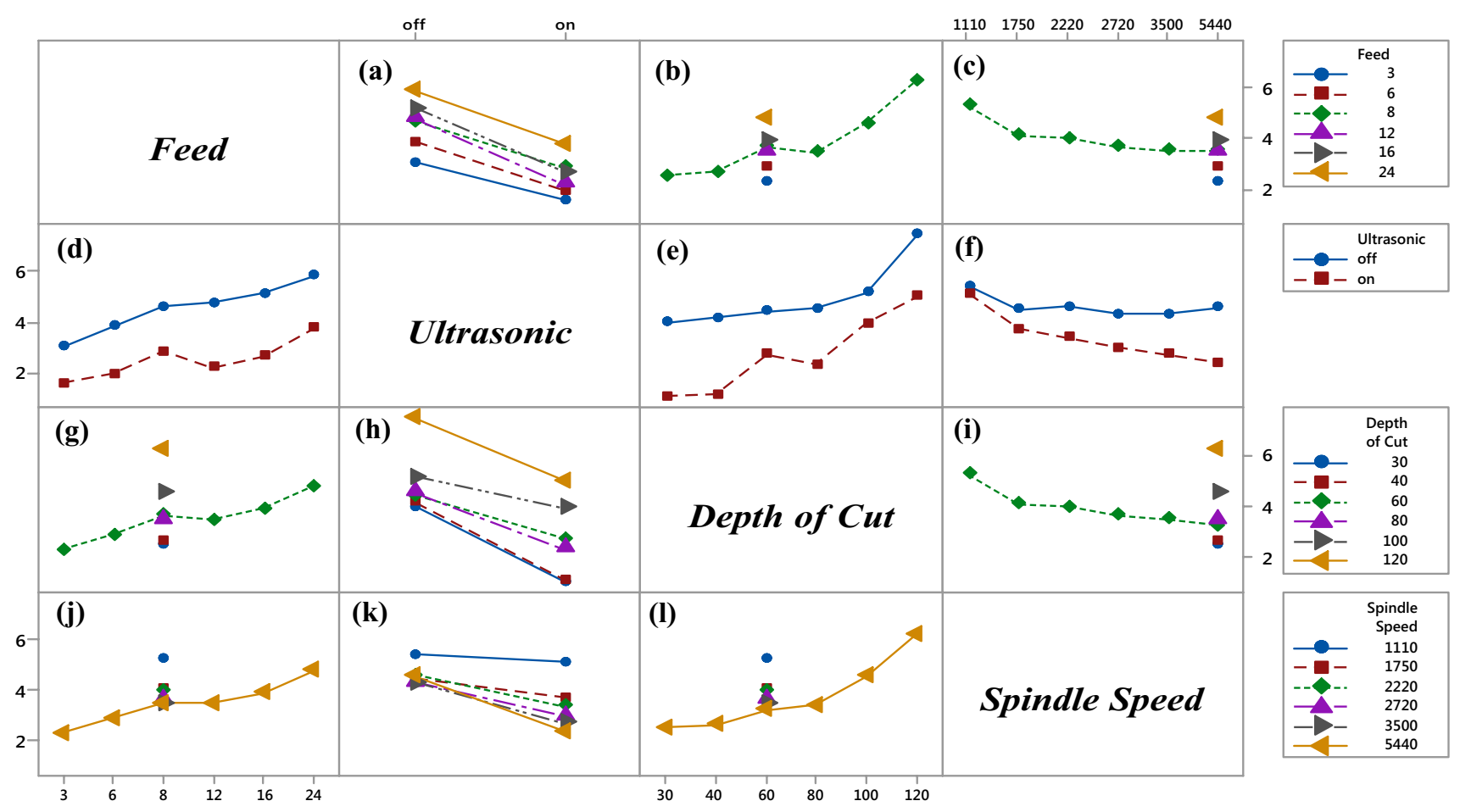

Fig. 7 Interaction plot for surface roughness

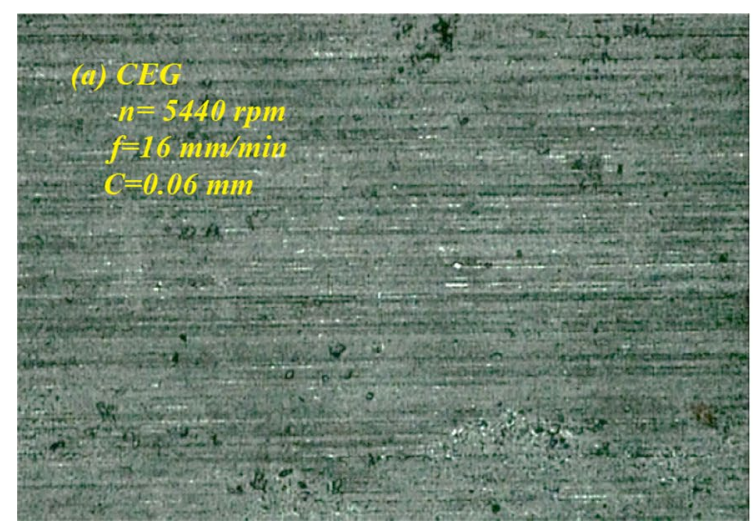

Fig. 8 Surface topology under CEG and RUAEG processes $(\times 34)$

and " $d$ " are closer to " 1 ", more ideal condition would be obtained. On the other hand, whatever approaches zero, one or a combination of response parameters is outside the range. The geometric mean value with the specified weights of each of " $d$ "s gives the value of D:

$D=\left(\prod\left(d_{i}^{w_{i}}\right)\right)^{\frac{1}{w}}$

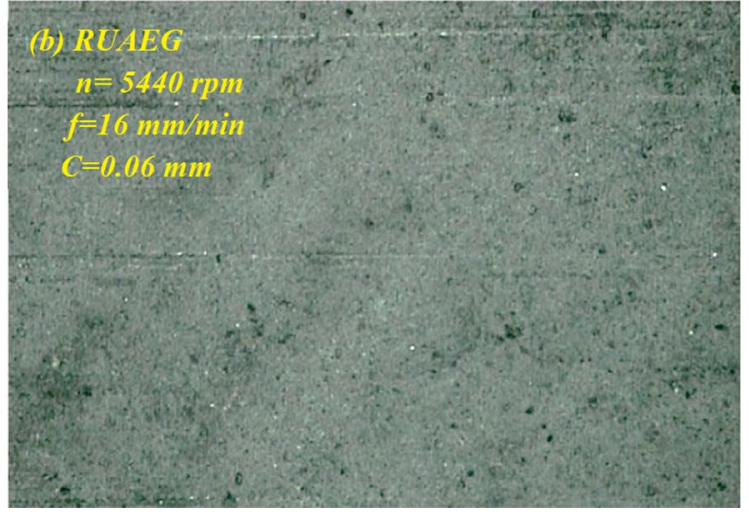

which if the value of the weights $\left(w_{i}\right)$ is the same, the relation becomes as follows:

$D=\left(d_{1} \times d_{2} \times \cdots \times d_{n}\right)^{\frac{1}{n}}$

That $d_{i}$ is distinct desirability concerning to the $i$ th respond, $w_{i}$ is influence of the ith respond, $w$ is sum of $w_{i}$ $\left(\sum w_{i}\right)$, and $\mathrm{n}$ is amount of responds. 

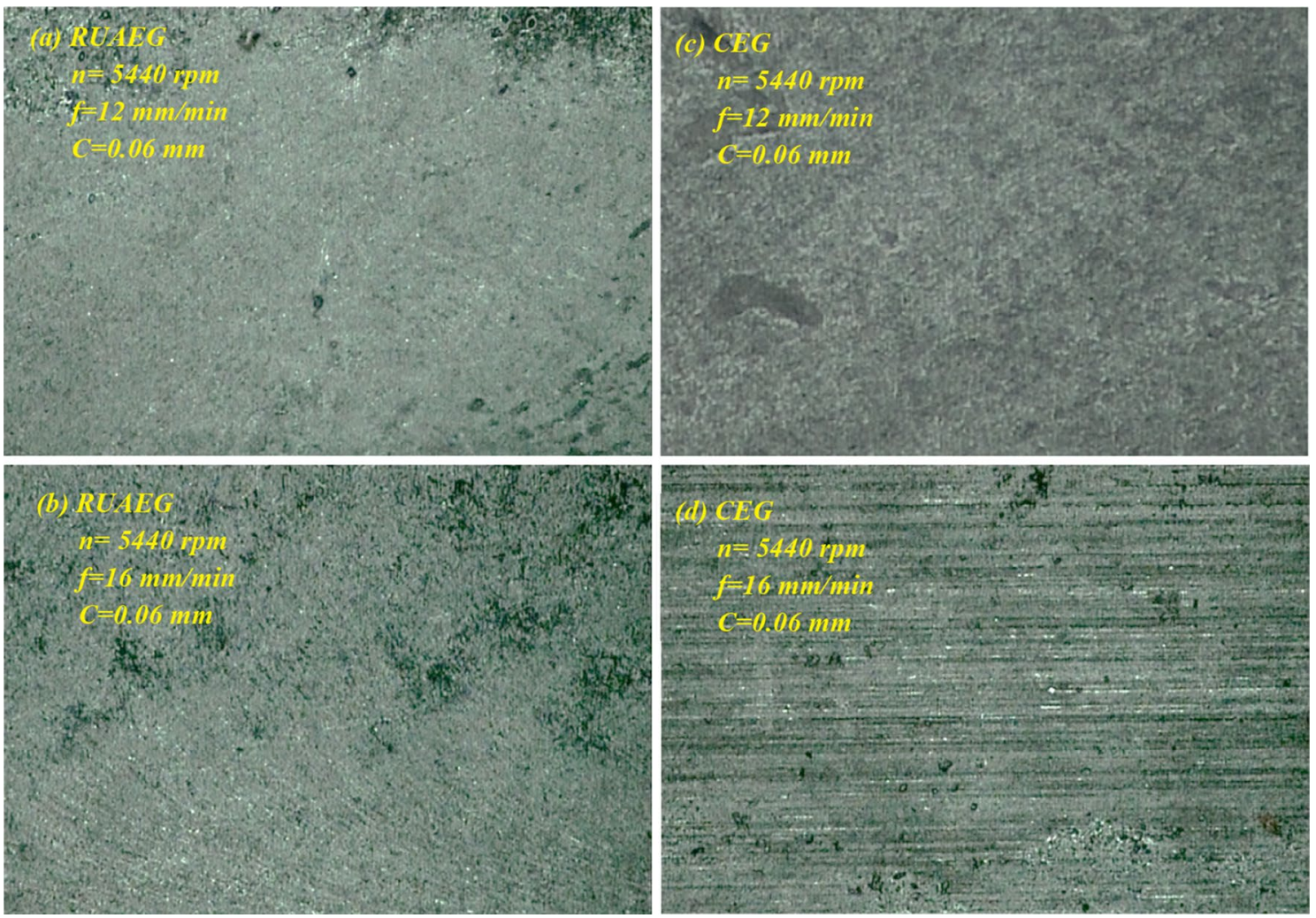

Fig. 9 Surface topology under CEG and RUAEG processes in different feed rates $(\times 34)$

\section{Conclusions}

In this investigation, rotary ultrasonic assisted end grinding of $\mathrm{Si}_{3} \mathrm{~N}_{4}$ using core drill were discussed. Thrust force and surface quality of the machined face in conventional end grinding and rotary ultrasonic assisted end grinding were inspected. Furthermore, to examine effect of the machining parameters, ANOVA was carried out. A suitable linear regression correlation in both CEG and RUAEG was presented. Following results were obtained:

1. Feeding speed increment induces thrust force increment in CEG more rapidly in comparing to RUAEG. Therefore, higher feeding speeds could be utilized with lower thrust forces by exerting ultrasonic vibration on the tool.
2. By statistical calculations, that is obtained the influence percentages of ultrasonic vibration on thrust force and surface roughness were respectively $29.36 \%$ and $42.96 \%$, which implies the most affective factor on thrust force and surface roughness is ultrasonic vibration.

3. By applying ultrasonic vibrations, higher feeding speed, rotational speed and cutting depth could be applied (means higher material removal speed) without more thrust force.

4. Due to applying ultrasonic waves, the tool impacts on the surface and causes the surface to be knocked, resulting in smoother surface and diminishing machining lines. Furthermore, size of scratches was lessened by applying ultrasonic vibration. 

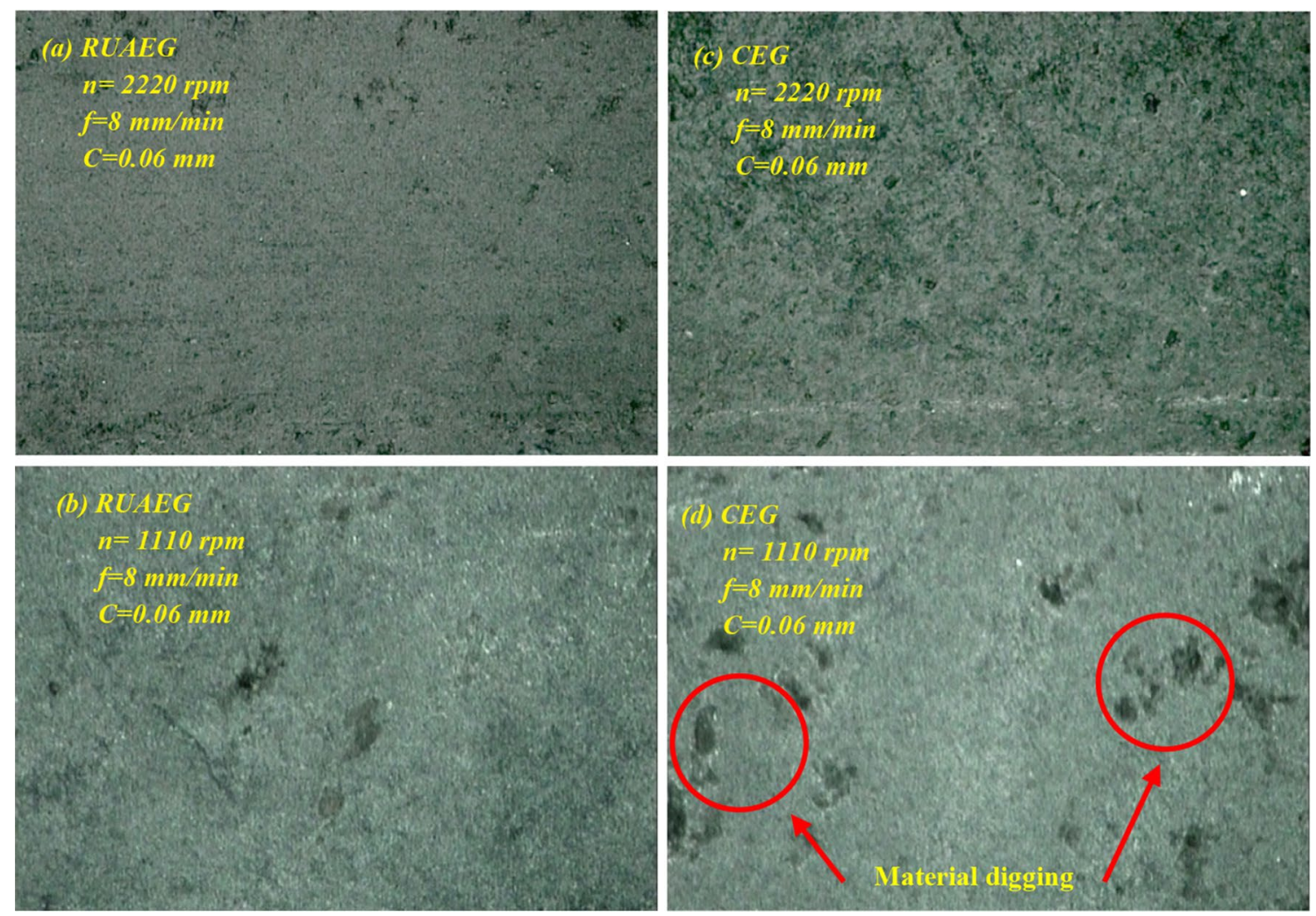

Fig. 10 Surface topology under CEG and RUAEG processes in different spindle speeds rates $(\times 34)$
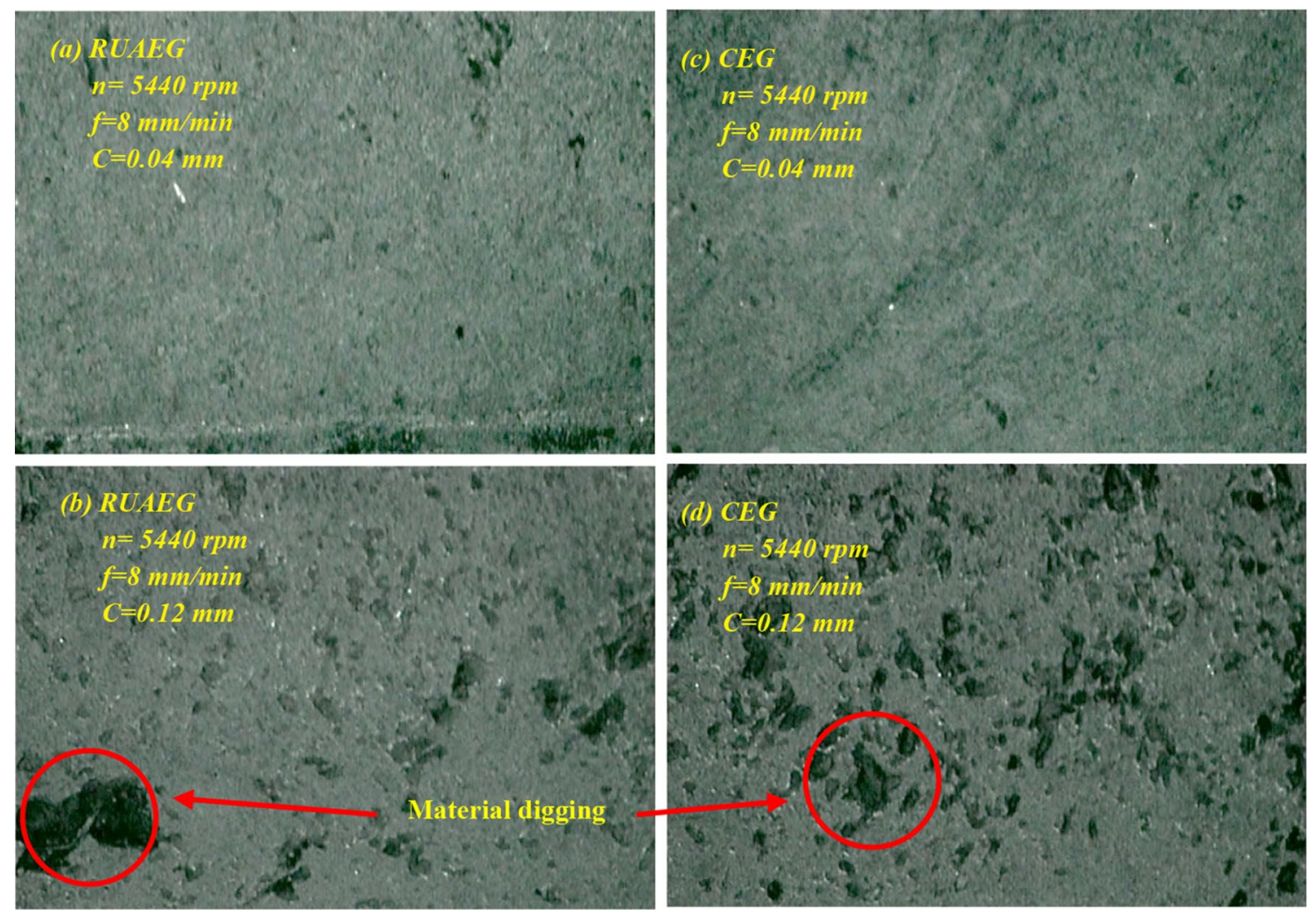

Fig. 11 Surface topology under CEG and RUAEG processes in different cutting depths (X 34)

\section{SN Applied Sciences}

a SPRINGER NATURE journal 


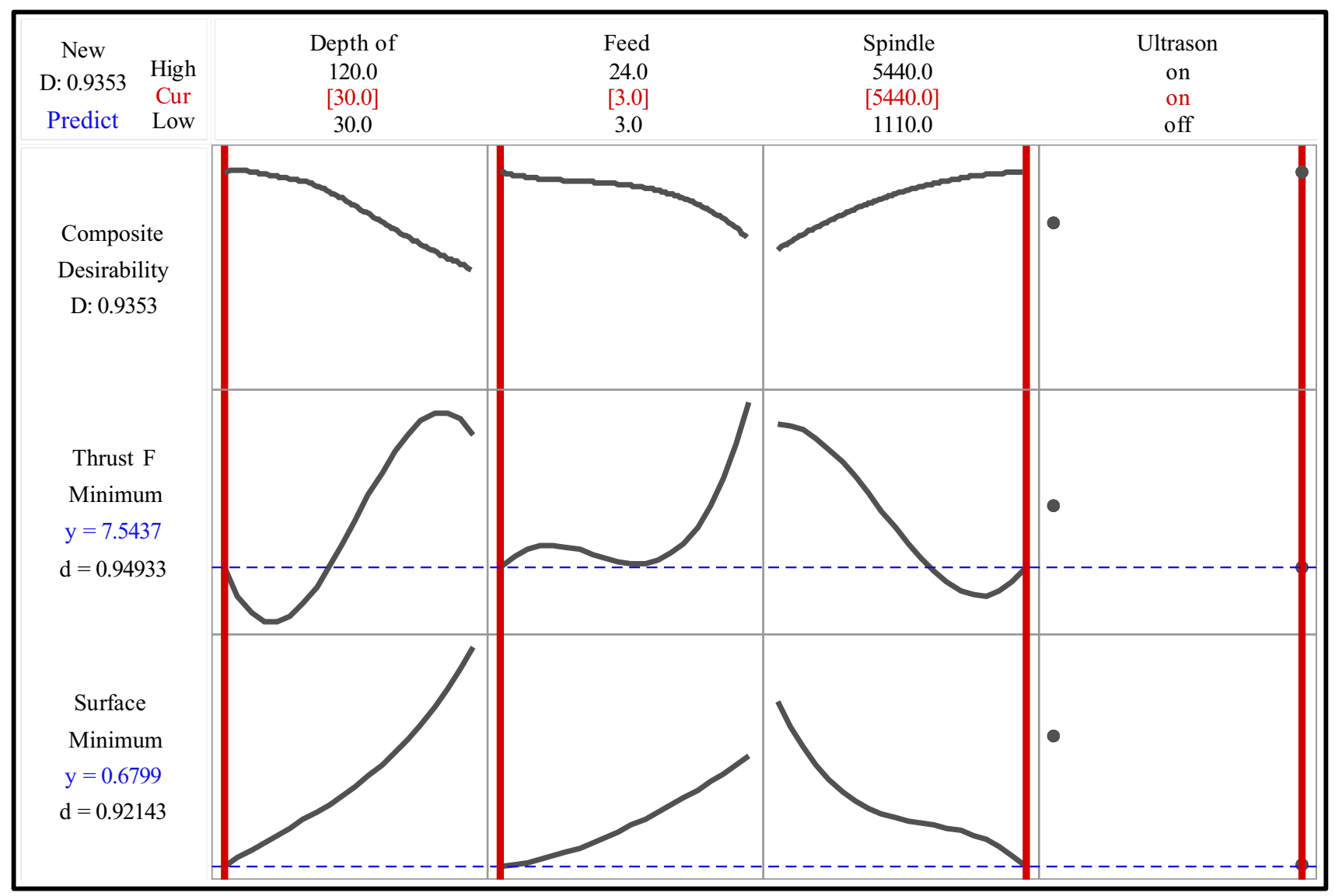

Fig. 12 Optimization plot

5. Optimization operation results that lower feeding speed and cutting depth and higher rotational speed plus ultrasonic vibration addition induce better surface quality and lower thrust force.

\section{Compliance with ethical standards}

Conflict of interest The authors declare that they have no conflict of interest.

\section{References}

1. Baraheni M, Amini S (2019) Predicting subsurface damage in silicon nitride ceramics subjected to rotary ultrasonic assisted face grinding. Ceram Int 45(8):10086-10096

2. Shankar S, Nithyaprakash R (2014) Wear prediction on silicon nitride bearing couple in human hip prosthesis using finite element concepts. Proc Inst Mech Eng Part J J Eng Tribol 228(7):717-724
3. Lin X, Ke X, Ye H, Hu C, Guo Y (2017) Investigation of surface/ subsurface integrity and grinding force in grinding of BK7 glass. Proc Inst Mech Eng Part C J Mech Eng Sci 231(12):2349-2356

4. Tönshoff H, Denkena B, Friemuth T, Glatzel T, Stahl M (2003) Grinding of a ceramic steel compound. Prod Eng 10:1-4

5. Kennedy D, Grieve R (1975) Ultrasonic machining-a review. Prod Eng 54(9):481-486

6. Azarhoushang B, Soltani B, Zahedi A (2017) Laser-assisted grinding of silicon nitride by picosecond laser. Int J Adv Manuf Technol 93(5-8):2517-2529

7. Samant AN, Dahotre NB (2009) Differences in physical phenomena governing laser machining of structural ceramics. Ceram Int 35(5):2093-2097

8. Sohrabpoor H, Mousavian RT, Obeidi M, Ahad I, Brabazon D (2019) Improving precision in the prediction of laser texturing and surface interference of $316 \mathrm{~L}$ assessed by neural network and adaptive neuro-fuzzy inference models. Int J Adv Manuf Technol 104(9-12):4571-4580

9. Sohrabpoor H, Negi S, Shaiesteh H, Ahad I, Brabazon D (2018) Optimizing selective laser sintering process by grey relational analysis and soft computing techniques. Optik 174:185-194

10. Blugan G, Herrmann T, Graule T, Kuebler J (2011) Laser machining of silicon nitride based composite cantilever structures. Opt Lasers Eng 49(9-10):1095-1100

11. Zhang X, Chen G, An W, Deng Z, Liu W, Yang C (2014) Experimental study of machining characteristics in laser induced wet grinding silicon nitride. Mater Manuf Process 29(11-12):1477-1482 
12. Sonkushre PK (2012) Advantages and disadvantages of laser cutting. http://www.buzzle.com/articles/advantages-and-disad vantages-of-laser-cutting.html. Accessed 4 Feb 2012

13. Azarhoushang B, Tawakoli T (2011) Development of a novel ultrasonic unit for grinding of ceramic matrix composites. Int J Adv Manuf Technol 57(9-12):945

14. Teimouri R, Amini S, Bami AB (2018) Evaluation of optimized surface properties and residual stress in ultrasonic assisted ball burnishing of AA6061-T6. Measurement 116:129-139

15. Xu L, Shen B, Shih AJ (2006) Vitreous bond silicon carbide wheel for grinding of silicon nitride. Int J Mach Tools Manuf 46(6):631-639

16. Biermann D, Würz E (2009) A study of grinding silicon nitride and cemented carbide materials with diamond grinding wheels. Prod Eng Res Dev 3(4-5):411

17. Ke Z, Jian S, He W, Yuhou W (2016) Experimental research on high speed grinding of silicon nitride ceramic spindle. In: Materials science forum

18. Stolarski T, Jisheng E, Gawne D, Panesar S (1995) The effect of load and abrasive particle size on the material removal rate of silicon nitride artefacts. Ceram Int 21(5):355-366

19. Dobrescu T, Pascu N, Opran C, Bucuresteanu A (2012) Subsurface damage in grinding silicon ceramics. In: Annals of DAAAM for 2012 and Proceedings of the 23rd international DAAAM symposium, ISBN

20. Kumabe J (1979) Fundamentals and application of vibration cutting. Jikkyo Publishing, Japan (in Japanese)

21. Tabatabaeian A, Baraheni M, Amini S, Ghasemi AR (2019) Environmental, mechanical and materialistic effects on delamination damage of glass fiber composites: analysis and optimization. J Compos Mater 53(26-27):3671-3680

22. Takeyama H, Kato S (1991) Burrless drilling by means of ultrasonic vibration. CIRP Ann Manuf Technol 40(1):83-86

23. Barani A, Amini S, Paktinat $H$, Tehrani AF (2014) Built-up edge investigation in vibration drilling of Al2024-T6. Ultrasonics 54(5):1300-1310

24. Baraheni M, Tabatabaeian A, Amini S, Ghasemi AR (2019) Parametric analysis of delamination in GFRP composite profiles by performing rotary ultrasonic drilling approach: experimental and statistical study. Compos B Eng 172:612-620

25. Uhlmann E, Spur G (1998) Surface formation in creep feed grinding of advanced ceramics with and without ultrasonic assistance. CIRP Ann 47(1):249-252

26. Amini S, Paktinat $H$, Barani A, Tehran AF (2013) Vibration drilling of AI2024-T6. Mater Manuf Process 28(4):476-480

27. Baraheni M, Amini S (2018) Feasibility study of delamination in rotary ultrasonic-assisted drilling of glass fiber reinforced plastics. J Reinf Plast Compos 37(1):3-12

28. Baraheni M, Amini S (2017) Study of the effect of machining parameters on delamination in rotary ultrasonic machining process of glass fiber reinforced polymer composite by diamond core tool. J Sci Technol Compos 4(1):66-74

29. Amini S, Baraheni M, Mardiha A (2018) Parametric investigation of rotary ultrasonic drilling of carbon fiber reinforced plastics. Proc Inst Mech Eng Part E J Process Mech Eng 232(5):540-554

30. Li Z, Jiao Y, Deines T, Pei Z, Treadwell C (2005) Rotary ultrasonic machining of ceramic matrix composites: feasibility study and designed experiments. Int J Mach Tools Manuf 45(12-13): 1402-1411

31. Kumar V, Singh H (2019) Rotary ultrasonic Drilling of Silica Glass BK-7: microstructural investigation and process optimization through TOPSIS. Silicon 11(1):471-485
32. Sindhu D, Thakur L, Chandna $P$ (2018) Multi-objective optimization of rotary ultrasonic machining parameters for quartz glass using Taguchi-Grey relational analysis (GRA). Silicon 11(4):2033-2044

33. Baraheni M, Amini S (2019) Comprehensive optimization of process parameters in rotary ultrasonic drilling of CFRP aimed at minimizing delamination. Int J Lightweight Mater Manuf. https ://doi.org/10.1016/j.ijlmm.2019.03.003

34. Zhang C, Zhang J, Feng P (2013) Mathematical model for cutting force in rotary ultrasonic face milling of brittle materials. Int $J$ Adv Manuf Technol 69(1-4):161-170

35. Zhang CL, Feng PF, Wu ZJ, Yu DW (2011) An experimental study on processing performance of rotary ultrasonic drilling of $\mathrm{K} 9$ glass. In: Advanced materials research. Trans Tech Publ

36. Brehl D, Dow T (2008) Review of vibration-assisted machining. Precis Eng 32(3):153-172

37. Amini S, Alinaghian I, Lotfi M, Teimouri R, Alinaghian M (2017) Modified drilling process of AISI 1045 steel: a hybrid optimization. Eng Sci Technol Int J 20(6):1653-1661

38. Ishikawa K-I, Suwabe H, Nishide T, Uneda M (1998) A study on combined vibration drilling by ultrasonic and low-frequency vibrations for hard and brittle materials. Precis Eng 22(4):196-205

39. Singh RP, Singhal S (2016) Rotary ultrasonic machining: a review. Mater Manuf Process 31(14):1795-1824

40. Lv D, Wang H, Tang Y, Huang Y, Li Z (2013) Influences of vibration on surface formation in rotary ultrasonic machining of glass BK7. Precis Eng 37(4):839-848

41. Ding K, Fu Y, Su H, Chen Y, Yu X, Ding G (2014) Experimental studies on drilling tool load and machining quality of $\mathrm{C} / \mathrm{SiC}$ composites in rotary ultrasonic machining. J Mater Process Technol 214(12):2900-2907

42. Cong W, Pei Z, Van Vleet EG, Wang Q (2009) Surface roughness in rotary ultrasonic machining of stainless steels. In: IIE annual conference. Proceedings. 2009. Institute of Industrial and Systems Engineers (IISE)

43. Jerold BD, Kumar MP (2012) Experimental comparison of carbon-dioxide and liquid nitrogen cryogenic coolants in turning of AISI 1045 steel. Cryogenics 52(10):569-574

44. Zhang C, Cong W, Feng P, Pei Z (2014) Rotary ultrasonic machining of optical K9 glass using compressed air as coolant: a feasibility study. Proc Inst Mech Eng Part B J Eng Manuf 228(4):504-514

45. Kuruc M, Vopát T, Peterka J (2015) Surface roughness of polycrystalline cubic boron nitride after rotary ultrasonic machining. Procedia Eng 100:877-884

46. Rowe WB (2013) Principles of modern grinding technology, 2nd edn. William Andrew, Norwich

47. Rabiei F, Rahimi A, Hadad M, Ashrafijou M (2013) Investigation of the effect of minimum quantity lubrication technique on performance of the grinding of HSS. Modares Mech Eng 13:1-12

48. Klocke F, Kuchle A (2009) Manufacturing processes, vol 2, 1st edn. Springer, Berlin

49. Yao Z, Gu W, Li K (2012) Relationship between surface roughness and subsurface crack depth during grinding of optical glass BK7. J Mater Process Technol 212(4):969-976

Publisher's Note Springer Nature remains neutral with regard to jurisdictional claims in published maps and institutional affiliations. 